\title{
Application of brazing process design in optimization structure design of scraper
}

\author{
Bin Zhao ${ }^{1,2}$, Yuanbin Fang ${ }^{1,2, a}$ and Linjie Zhang ${ }^{3}$ \\ ${ }^{1}$ Jiangsu XCMG Construction Machinery Research Institute Co., Ltd, Jiangsu Xuzhou, China \\ ${ }^{2}$ State key Laboratory of Intelligent Manufacturing of Advanced Construction Machinery, XCMG Construction Machinery Co., Ltd, \\ Jiangsu Xuzhou, China \\ ${ }^{3}$ School of Material Science and Engineering, Xi'an Jiaotong University, Shanxi Xi'an, China
}

\begin{abstract}
To effectively enhance the service life, the research of milling machine scraper structure design and welding process are optimized. Through the structural optimization analysis, the improved structure is obtained, and the working resistance force is reduced. The full factor test is used to optimize the brazing process, and the best parameters are obtained, which improves the shear strength. The accuracy of the model is verified by experiments. The results show that compared with the working resistance force, the improved scraper tends to be slow and the peak value is smaller. The cutting rake and relief angle of the scraper are optimized. When the cutting rake angle is $6^{\circ}$ and the cutting relief angle is $9^{\circ}$, both working resistance force and impact force are minimum. It proves the accuracy of the simulation results. Using CT861 solder, brazing temperature is $75^{\circ} \mathrm{C}$, and the brazing time is $10 \mathrm{~s}$. While the cooling method uses furnace cold, the minimum value of shear strength is $200 \mathrm{MPa}$. The average working life of the scraper is raised from 800 hours to 1600 hours after the optimization design. Research results have guiding significance for the structure design and the welding process optimization of the scraper.
\end{abstract}

\section{Introduction}

The service life of milling machine scraper is important index to improve the performance of the products. In milling, the milling cutter, the scraper, the slipper plate and the throwing-out plate are used mainly with the waste materials such as asphalt. The pavement is broken into particles in the impact and compression of the milling cutter. The waste of pavement, in the working resistance force of the scraper at the bottom of receiving plate and the side door slipper plate under and impact force of the pavement sharp, is collected together and thrown onto the conveyor by the throwing-out plate. By the wear of the scraper, the gap between the collecting plate and the pavement increases which results in making the collecting waste effect poor. The scraper has the advantages of low working resistance force and high wear resistance, which is beneficial to the service life. Milling efficiency, collecting waste effect and service life are the key indicators [1]. Therefore, the structure design of the scraper and the welding process optimization are very important. In the process of product design, the Germany WIRTGEN considers the process realization of scraper and structure design under working force. The optimal design improves the service life of the scraper.

With the maturity of finite element technology and structural optimization method, simulation technology has become an effective means of structural design, which directly affects the performance of products. The evaluation of the service life is very high in addition to the reasonable structure design. The scraper connects the cemented carbide and the substrate through the brazing process. There are many methods for brazing process design, such as [2], experience accumulation, the full factor test, the orthogonal test [3] and so on. Yan F. et al [4] used ANSYS to simulate the brazing temperature field of the scraper. The process of brazing copper to aluminum with $\mathrm{Al} \mathrm{Si} \mathrm{solder} \mathrm{was} \mathrm{simulated.} \mathrm{The} \mathrm{rare}$ earth $\mathrm{La}$ promoted the diffusion of intermetallic compounds to the brazing seam, and significantly improved the microstructure and mechanical properties of joints. Shi J. W. et al [5] described of heating factor q as the evaluation indexes of different manufacturers in the reflow process and used to evaluate the reliability of reflow process. The research pointed out that $\mathrm{q}$ was directly related to the energy absorbed by the solder and the form of the intermetallic compound formed between the solder and the weld plate. Khorram A. et al [6] studied the effect of laser power, velocity and pulse width on the geometry of brazing by response surface methodology. Then the brazing process was optimized by optimization for multiple responses, and the optimum parameter is determined. Song Y. F. et al [7] researched that the shear strength of brazed joint was analyzed with the influence factor of brazing time. It is found that the brazing time of the joint changed with microstructure. Therefore, the parameters of the brazing are optimized

$\overline{{ }^{a} \text { Corresponding author: fybflying@ } 163 . c o m}$ 
by means of the optimization test to improve the mechanical properties. With the continuous research of fatigue mechanism, how to effectively improve the fatigue life has become a difficult problem to be solved in the engineering application [8]. At present, the brazing process can be achieved through the optimization test and the welding process evaluation, but the optimization method needs some experience to accumulate. The full factor test has taken into account the characteristics of the brazing process, which is sensitive to parameters, and becomes an effective optimization method.

At present, many experts and scholars have done much research on structural design optimization and brazing process optimization methods. Through the empirical method, Pascal D. T. et al [9] optimized the brazing process parameters of metal composite coating to determine the best process parameter. Ju J. et al [10] studied the relationship between microstructure and properties of welded joints. The influence parameters were analyzed with the decrease of heating speed or the increase of brazing temperature, and the shear strength of joints was analyzed. Riggs B. B. et al [11] predicted brazing high strength nickel base single crystal super alloy by dynamic and thermodynamics, and simulated in different brazing temperature, holding time and joint gap.

The above research results are mainly studied from the single structural design or brazing process design to the performance and service life of the parts, while the research on both structural design and process design are few. Based on this, from structure design and process design of road milling machine scraper, this research simulates and improves working situation to reduce the impact force and work resistance by the optimized scraper structure design. The influence of the installation angle of cemented carbide on the mechanical behavior is analyzed. The cutting rake angle and relief angle are designed to reduce the impact and work resistance of scrapers. On structural optimization, the brazing process design is taken into account, and the full factor test is used to optimize the brazing process parameters.

\section{Methodology}

\subsection{Establish the mechanical model of unimproved scraper}

The unimproved scraper is that the cemented carbide is inlaid to the scraper substrate. The scraper substrate uses 345 steel. The cutting rake angle of the cemented carbide and the pavement is $9^{\circ}$, and the cutting relief angle of the scraper substrate and the pavement is $78^{\circ}$. The hardness of the scraper is larger than that of the asphalt concrete pavement. In the process of milling, the tool is almost not deformed to define a rigid body during the model. The asphalt concrete pavement is based on the HJC constitutive model. The density of the scraper is $7.8 \times 10^{3}$ $\mathrm{kg} / \mathrm{m}^{3}$, the modulus of elasticity is $2.1 \times 10^{11} \mathrm{~Pa}$, and the Poisson's ratio is 0.3 .

To ensure the accuracy of model, the scraper mesh is divided into hexahedral units, and the size is about
$0.5 \mathrm{~mm}$. The nodes are 318912, and units are 304413, as shown in Figure 1.

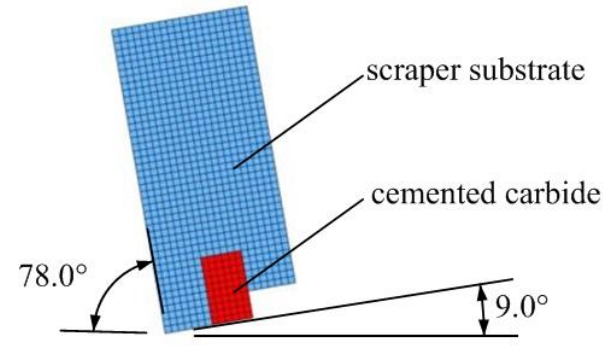

Figure 1. The finite element model of the scraper

In milling process of the milling machine, to avoid the initial penetration between the scraper and the pavement, surface-surface erosion is defined as contact. The failure of the pavement is broken into granular, and the failure criterion of the pavement material is defined by the $\mathrm{K}$ file. Non-reflection boundary conditions are applied to not be in direct contact with the scraper surface, and decrease the effect of force on the scraper cutting process. To ensure the accurate contact force, the contact force is extracted by $\mathrm{K}$ file. The moving speed of the scraper is $11.6 \mathrm{~mm} / \mathrm{s}$, and the calculation time is $1.5 \mathrm{~s}$. The finite element model of the scraper and the pavement is set up.

\subsection{Performance analysis of unimproved scraper material}

Using handheld $\mathrm{X}$ ray composition analyzer and THRP150D digital Rockwell hardness tester, the main chemical composition and hardness of the scraper carbide are tested. The results show that the content of $\mathrm{W}$ is $93 \%$, the content of Co is $6 \%$, and the hardness is 85.9HRC. It is known that the main components of the cemented carbide are $\mathrm{W}$ and $\mathrm{Co}$, and the alloys are preliminarily identified as WC-Co series. In the series of cemented carbide, the hard phase is WC particles, and Co is used as an adhesive. When the Co is low, the hardness of the cemented carbide is high, but the impact resistance of the cemented carbide is poor. The $\mathrm{W}$ content of the cemented carbide used in the unimproved scraper is higher, the content of Co is slightly lower, the hardness is high, and the section is rectangular.

The scraper is torch soldering with copper wire. By the limitation of scraper structure, it is easy to produce bad fusion defects when brazing, so its joint shear strength is low. To evaluate the shear strength of the unimproved scraper, the joint of the butt plate is evaluated. The first step is to design the tooling to tighten the sample, and designs the $\mathrm{L}$ base that is machined the rectangular section on the vertical side. Then the joint sample is put into the shear test, and it obtains the shear strength of $84 \mathrm{Mpa}$.

\subsection{Dynamic analysis of the unimproved scraper}

In the working process of milling machine scraper, the scraper is forward in working resistance force, which reduces the wear resistance of the scraper, by waste in 
the horizontal direction. Through the dynamic simulation of the working condition, the working resistance force of the unimproved scraper is obtained, as shown in Figure 2.

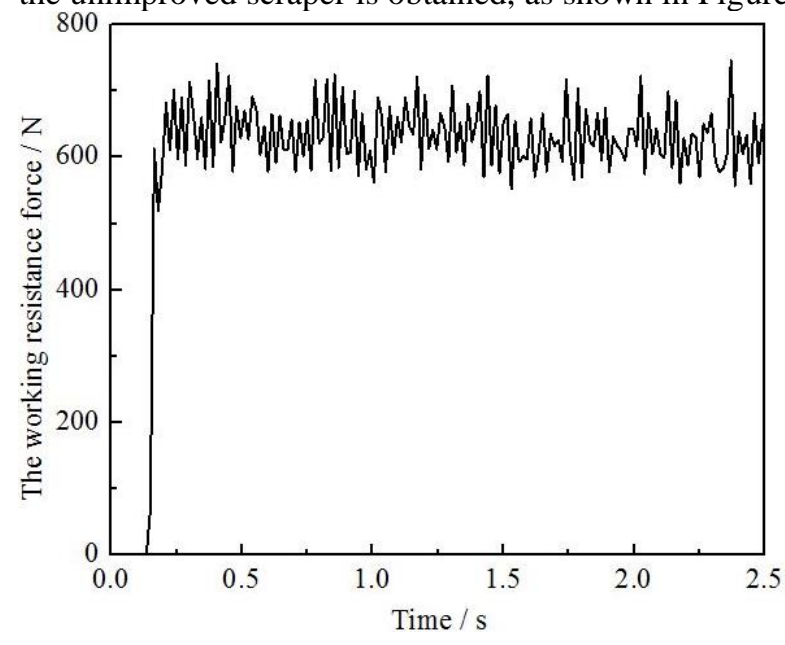

Figure 2. The working resistance force of the unimproved scraper

In Figure 2, the working resistance force of the unimproved scraper is large, and the amplitude fluctuates greatly. The milling process is easily damaged by the impact and wear, and the wear resistance of the scraper is reduced. Because of the cemented carbide in contact with the pavement initial surface is not reasonable, the cemented carbide need sustain more working resistance force and impact force. The wear of scraper substrate and the front cemented carbide is serious to be easy premature failure, seriously affecting work efficiency. The installation position of cemented carbide design is not reasonable that the front of the cemented carbide just play a role. The pavement is quite small to make the cemented carbide utilization rate extremely low. The scraper substrate and the relief angle first contact with the road pavement, causing serious wear of scraper substrate. Therefore, the design of cemented carbide at the bottom of the scraper substrate is not reasonable, and the design of scraper structure is improved.

\section{Result analysis and discussion}

\subsection{Establish the mechanical model of improved scraper}

The scraper cemented carbide is the main part of the load, and the contact between the scraper substrate and the pavement should be avoided in the design. Considering the original brazing process, the substrate groove often exist bad connection, resulting in lower bonding strength of scraper, so the shear strength is too low. So it is necessary to move the cemented carbide forward, which is beneficial to the realization of the brazing process, and can make the cemented carbide contact directly with the pavement. Considering the effect of waste discharge, there is a certain relief angle of cemented carbide and the pavement. The scraper is fixed on the receiving plate. There is a certain angle between the receiving plate and the pavement. Therefore, it is necessary to design the cutting rake angle of the cemented carbide and the scraper substrate and the cutting relief angle of the scraper substrate and the pavement. The cutting rake angle is $10^{\circ}$, and the cutting relief angle is $10^{\circ}$. Compared with the unimproved scraper, the carbide section shape is a right-angle trapezium, which is more conducive to milling the pavement.

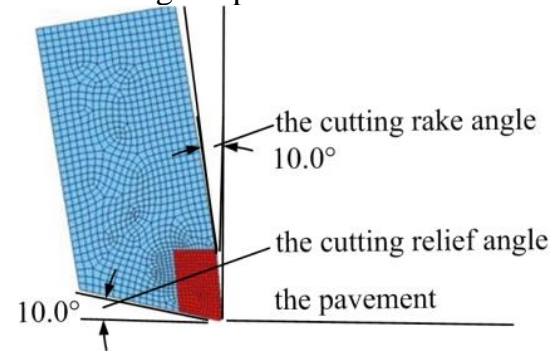

Figure 3. The finite element model of the improved scraper

Similarly, the improved scraper is meshed. There are 323546 nodes and 310957 units, as shown in Figure 3. The failure criterion and contact definition of pavement materials are the same as those of the above model.

\subsection{Optimization and analysis of the cutting angle}

To study the force of the cutting rake and relief angle, the posture of the scraper is adjusted. The cutting rake angle is changed from $2^{\circ}$ to $12^{\circ}$ and the cutting relief angle is adjusted from $1^{\circ}$ to $11^{\circ}$. The calculation results are extracted. As the simulation analysis, the working force results of the cutting rake angle and the cutting relief angle are shown in Table 1.

Table 1. The working force of the cutting rake and relief angle.

\begin{tabular}{|c|c|c|c|c|c|c|}
\hline The cutting rake angle $\left[^{\circ}\right]$ & 2 & 3 & 4 & 5 & 6 & 7 \\
\hline Average force $[\mathrm{N}]$ & 336 & 518 & 566 & 576 & 640 & 640 \\
\hline The impact force $[\mathrm{N}]$ & 488 & 622 & 460 & 204 & 51 & 196 \\
\hline The cutting rake angle $\left[^{\circ}\right]$ & 8 & 9 & 10 & 11 & 12 & - \\
\hline Average force $[\mathrm{N}]$ & 596 & 594 & 580 & 571 & 559 & - \\
\hline The impact force $[\mathrm{N}]$ & 247 & 210 & 120 & 151 & 241 & - \\
\hline The cutting relief angle $\left[{ }^{\circ}\right]$ & 1 & 2 & 3 & 4 & 5 & 6 \\
\hline Average force $[\mathrm{N}]$ & 640 & 633 & 627 & 630 & 624 & 636 \\
\hline The impact force $[\mathrm{N}]$ & 52 & 57 & 73 & 54 & 71 & 57 \\
\hline The cutting relief angle $\left[{ }^{\circ}\right]$ & 7 & 8 & 9 & 10 & 11 & - \\
\hline Average force $[\mathrm{N}]$ & 635 & 629 & 629 & 629 & 630 & - \\
\hline The impact force $[\mathrm{N}]$ & 58 & 63 & 53 & 68 & 67 & - \\
\hline
\end{tabular}

From table 1 , when the working angle is $6^{\circ}$, the impact force is minimum that the value is $51 \mathrm{~N}$. The resultant force is minimum that the value is $691 \mathrm{~N}$. When the working angle is $10^{\circ}$, the resistance and impact force are bigger than that of $6^{\circ}$. The decrease of the impact force reduces the wear of the scraper and improves the service life of the cemented carbide.

The cutting relief angle has little influence on the force. The cutting relief angle depends on the shape of the cemented carbide, and affects the scraper strength. Therefore, considering the strength and the shape of the cemented carbide, the cutting relief angle is $9^{\circ}$. 
Similarly, the working process of the improved scraper is simulated, and the working resistance force is obtained. The working resistance force of the unimproved and improved scraper is compared, as shown in Figure 4. From Figure 4, the improved working resistance force tends to be slow and the peak value is smaller.

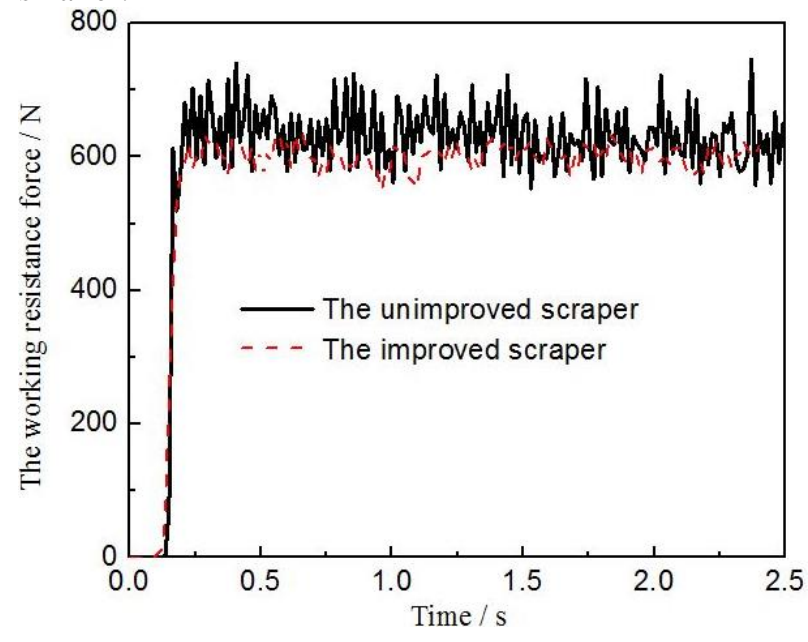

Figure 4. The compared working resistance force of the scraper

\subsection{Optimization design and verification of brazing process}

With the disadvantages of copper base solder, the silver base solder used in cemented carbide is selected. BAg616 silver base solder has Ag content of 50\% and melting temperature of $678-695^{\circ} \mathrm{C}$. The solder has good wettability and high brazing strength to be suitable for brazing hard wetting materials. Sandwich composite solder with copper sheet helps prevent cracks. The CT861 Sandwich solder has a melting temperature of $640-695^{\circ} \mathrm{C}$. The solder has good impact resistance and can effectively prevent the cracking of cemented carbide after welding, and is suitable for induction brazing.

The thermal expansion coefficient of cemented carbide and scraper substrate is quite different, which is general $1 / 2 \sim 1 / 3$ of steel. It cannot synchronously shrink after welding to be high residual stress in weld seam, resulting in cracking of cemented carbide. The copper brazing solder is melting temperature of $890 \sim 909^{\circ} \mathrm{C}$, which is about $200^{\circ} \mathrm{C}$ higher than that of silver based solder. It will cause large deformation and racking of cemented carbide. And the silver base solder Bag616 has a high cost. Therefore, considering the welding requirements of the actual scraper and the melting temperature and cost of the solder, the silver sandwich solder CT861 is selected.

After determining the solder brand, the three factors and three levels full factorial test method is applied to design the brazing process. The parameters include brazing temperature, time and cooling mode, and the evaluation index is shear strength. Three factors and three levels are shown in Table 2.

First, sandblasting is used to remove the oxide skin. After that, acetone is used to remove grease and dust.
Then the brazing filler metal and flux are added to the induction brazing, and then the heat treatment after welding is carried out. As the strength test standard of brazing joint, the shear strength of the specimen is measured. The results are shown in Table 3.

Table 2. The working force of the cutting rake and relief angle.

\begin{tabular}{|c|c|c|c|}
\hline The three levels & 1 & 2 & 3 \\
\hline Temperature $\left[{ }^{\circ} \mathrm{C}\right]$ & 690 & 720 & 750 \\
\hline Time $[\mathrm{s}]$ & 10 & 20 & 30 \\
\hline Cooling mode & air cooling & $\begin{array}{c}\text { insulation } \\
\text { cotton }\end{array}$ & $\begin{array}{c}\text { furnace } \\
\text { cold }\end{array}$ \\
\hline
\end{tabular}

Table 3. The shear strength of brazing joint test.

\begin{tabular}{|c|c|c|c|c|c|c|}
\hline Test & 1 & 2 & 3 & 4 & 5 & 6 \\
\hline Temperature $\left[{ }^{\circ} \mathrm{C}\right]$ & 720 & 690 & 720 & 690 & 720 & 750 \\
\hline Time $[\mathrm{s}]$ & 20 & 10 & 20 & 30 & 20 & 30 \\
\hline Cooling mode & 2 & 3 & 2 & 1 & 2 & 1 \\
\hline Shear strength $[\mathrm{N}]$ & 190 & 139 & 136 & 178 & 197 & 178 \\
\hline Test & 7 & 8 & 9 & 10 & 11 & 12 \\
\hline Temperature $\left[{ }^{\circ} \mathrm{C}\right]$ & 750 & 690 & 720 & 750 & 690 & 750 \\
\hline Time $[\mathrm{s}]$ & 30 & 10 & 20 & 10 & 30 & 10 \\
\hline Cooling mode & 3 & 1 & 2 & 3 & 3 & 1 \\
\hline Shear strength $[\mathrm{N}]$ & 172 & 145 & 198 & 200 & 177 & 171 \\
\hline
\end{tabular}

By analyzing and optimizing the shear strength results, the best brazing process with the maximum shear strength is obtained. The brazing temperature is $750^{\circ} \mathrm{C}$. The brazing time is $10 \mathrm{~s}$, and the cooling mode is furnace cooling. The maximum shear strength is $200 \mathrm{MPa}$.

With the design size requirements of the improved scraper, the test sample of the scraper is processed. The brazing optimization process uses to be connected cemented carbide with the scraper substrate. The scraper sample is installed and tested, as shown in Figure 5. The average working time of scrapers is from 900 hours to 1800 hours, and the test sample meets the requirements of the milling machine performance.

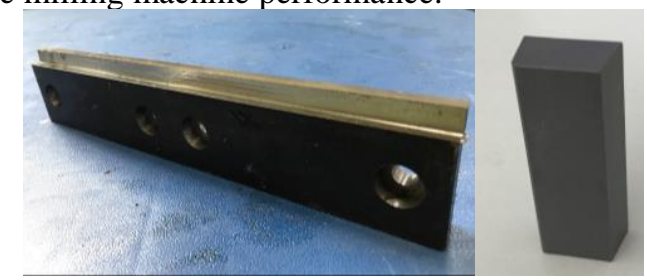

(a) The scraper substrate and cemented carbide sample

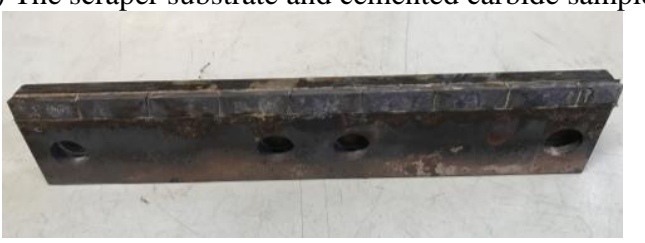

(b) The improved scraper

Figure 5. The scraper sample

\section{Conclusions}

To effectively improve the service life of the scraper, considering the structural design and welding process design of milling machine scraper, this research analyzes 
the unimproved scraper model and the copper brazing process by the dynamics analysis and test. The installation of cemented carbide is designed for different cutting rake and relief angle of dynamics simulation. By analyzing, the reasonable solder is selected. The brazing process is optimized to improve shear strength by the full factorial test. Finally the scraper sample is installed and tested. The following conclusions are drawn through the research:

(1) The structure of the scraper is improved that the cemented carbide is moved forwards the scraper substrate. The cutting rake and relief angle are optimized to reduce the working resistance force and the impact force.

(2) Compared with the working resistance force of the unimproved scraper, the improved working resistance force tends to be slow. The peak value and the impact are smaller.

(3) It helps to increase the shear strength that selecting the reasonable silver base solder and optimizing the process parameters of brazing.

(4) Considering the structural and brazing process optimization design, the service life of scrapers can be effectively improved that the average working life of scrapers will be increased by $100 \%$.

\section{References}

1. A. Bryan, J. Mech. Sci. Technol. 31, 1 (2017)

2. M. Kim, C. Park, J. Mech. Sci. Technol. 31, 5 (2017)

3. Y.B. Fang, X.M. Zong, H.Q. Zhang, X.Q. Yin, L. J. Zhang, T. Chin. Weld. I. 38, 8 (2017)

4. C. Krzysztof, K. Andrzej, Stud. Geotech. Mech. 38, 2 (2016)

5. J.W. Shi, P. He, X.C. Lv, Int. J. Mod. Phys. B 23, 67 (2009)

6. A. Khorram, M. Ghoreishi, Laser. Eng. 31, 5-6 (2015)

7. Y.F. Song, L.R. Xiao, X.J. Zhao, H. Zhou, W. Zhang, L. Guo, Y.H. Wang, Mater. Manuf. Process. 31 (2016)

8. H.J. Wang, Q. Zhang, F. Xie, IET Sci. Meas. Technol. 11, 7 (2017)

9. D.T. Pascal, V.A. Serban, G. Marginean, Solid State Phenom. 254 (2016)

10. Ju J.; Xue F.; Zhou J.; Bai J.; Sun L. X. Mater. Manuf. Process. 31 (2016)

11. Riggs B.B.; Alexandrov B.B.; Benatar A.A.; Xu R.R. Science and Technology of Welding and Joining 22, 5 (2017) 